\title{
Farklı NaCl ve jasmonik asit konsantrasyonlarının yem bezelyesinde (Pisum arvense) bitki gelişimine etkisi*
}

\author{
Özlem ÖNAL AȘCI ${ }^{1}$, Aylin ERIŞ̧ ${ }^{2}$ \\ 1Ordu Üniversitesi Ziraat Fakültesi Tarla Bitkileri Bölümü, Ordu \\ 20rdu Üniversitesi Fen Bilimleri Enstitüsü Tarla Bitkileri Anabilim Dalı, Ordu \\ *Bu çalışma Ordu üniversitesi BAP Koordinatörlüğü tarafından desteklenmiştir (Proje No TF 1625) \\ Alınış tarihi: 11 Aralık 2018, Kabul tarihi: 13 Şubat 2019 \\ Sorumlu yazar: Özlem ÖNAL AȘCI, e-posta: onalozlem@hotmail.com
}

\section{Öz}

$\mathrm{Bu}$ çalışma, yem bezelyesi (Pisum arvense)'nin Gölyazı çeşidinde farklı tuz ve jasmonik asit konsantrasyonlarının bitki gelişimi üzerine etkisini belirlemek amacıyla sera koşullarında saksıda yapılmıştır. Bitkilere 4 farklı tuz konsantrasyonu (0, $25,50,75 \mathrm{mM} \mathrm{NaCl}$ ) ve 3 farklı jasmonik asit (JA) konsantrasyonu $(0,50,100 \mu \mathrm{M} \mathrm{JA})$ uygulanmıștır. Fidelerde 4. gerçek yapraklar çıktığında JA yapraktan uygulanmıştır. JA uygulamasından 3 gün sonra saksılara tuz ilave edilmiştir. Araştırmada bitki boyu, kök uzunluğu, yaprakçık sayısı, toprak üstü yaş ve kuru ağırlık, kök yaş ve kuru ağırlık, toplam klorofil miktarı, yaprağın oransal su içeriği, prolin miktarı, membran zararlanması, $\mathrm{Na}$ oranı belirlenmiştir. Araştırma sonucunda hem bitki boyunun hem de toprak üstü yaş ağırlığın $75 \mathrm{mM} \mathrm{NaCl}$ uygulamasında önemli düzeyde azaldığı belirlenmiştir. Hem tuz hem de JA uygulaması bitkide yaprakçık sayısını azaltmıştır. En yüksek kök yaş ve kuru ağırlığı ise 50 $\mu \mathrm{M}$ JA ve $25 \mathrm{mM}$ NaCl'ün birlikte uygulandığ bitkilerde belirlenmiştir. Çalışmada incelenen diğer özelliklerin ise tuz ve JA uygulamasindan etkilenmediği belirlenmiștir.

Anahtar kelimeler: Bezelye, jasmonik asit, stres, tuz

The effect of different salt and jasmonic acid concentrations on plant growth of forage pea (Pisum arvense)

\section{Abstract}

This study was carried out in glasshouse as pot experiment to determine the effect of different salt and jasmonic acid concentrations on plant growth of forage pea (Pisum arvense) cv. Gölyazı. The plants were subjected to 4 different salt doses $(0,25,50,75$ $\mathrm{mM} \mathrm{NaCl}$ ) and 3 different concentrations of jasmonic acid $(0,50,100 \mu \mathrm{M} \mathrm{JA})$. When the fourth leaves were grown in seedlings, JA was applied to the leaves. 3 days after the application of JA salt was added to the pots. In the study, plant height, root length, number of leaflets, aboveground fresh and dry weight, root fresh and dry weight, chlorophyll, proline, relative water content, $\mathrm{Na}$ content and membrane damage values were investigated. As a result of experiment, it was determined that both plant height and aboveground fresh weight decreased significantly at $75 \mathrm{mM} \mathrm{NaCl}$. Both salt and JA application reduced the number of leaflets in the plant. The highest root fresh and dry weight were determined in plants treated with $50 \mu \mathrm{M} \mathrm{JA}$ and $25 \mathrm{mM} \mathrm{NaCl}$. The other characteristics of the study were not affected by salt and JA application.

Key words: Pea, jasmonic acid, stress, salt

\section{Giriş}

Tuzluluk, tarımsal üretim alanlarında bitki büyümesi, verimi ve kalitesini sınırlandıran en önemli sorunların başında gelmektedir (Öztürk, 2004). Tuz stresi bitkinin suyu topraktan alamamasına ve iyon toksiditesine neden olmaktadır (Dölarslan ve Gül, 2012). Yetiştirilecek bitki çeşidi, tuzluluğun belli düzeylerin altına düşürülemediği alanlarda, ekonomik düzeyde ürün elde edebilmek açısından önemlidir (Ekmekçi ve ark., 2005). Bu nedenle bitkilerin tuza tepkileri incelenmeye başlanmıştır. Bezelye ile yürütülen çalışmalarda tuz stresinin bitki gelişimini olumsuz etkilediği belirlenmiştir (Bilgili ve ark., 2011; Önal Așcl ve Üney, 2017; Demirkol ve ark., 2018). Birçok yem 
bitkisi türünün rahatlıkla yetiștirilebileceği ülkemizde yetiştirilen tür sayısı oldukça sınırlı olup, genellikle tek yıllık türler tercih edilmektedir. Tek ylllk serin mevsim bitkisi olan yem bezelyesi, hem kaba yem hem de kesif yem amaciyla yetiştirilebilecek türlerden birisidir. Ülkemizde son yıllarda yem bezelyesi yetiştiriciliğinin yaygınlaştığı, 2017 yılında yaklaşık 70 bin da alanda ekildiği görülmektedir (TÜİ, 2018). Tuz stresinin bitkilerdeki olumsuz etkilerini azaltmak amaciyla bazı uygulamalar yapılmaktadır. Jasmonatların değişik stres ve zararlı saldırılara karşı bitkinin dayanımını arttırdığı tespit edilmiştir. Fedina ve Tsonev (1997), bezelye fidelerine (Pisum sativum L.), 10-5 M MeJA uygulamışlar ve fideleri tuzlu koşullarda yetiştirmişlerdir. Araştırma sonucunda bitki gövdelerinde $\mathrm{Na}^{+}$ve $\mathrm{Cl}^{-}$iyonlarının birikiminin azaldı̆̆ı gözlenmiștir. Buğday (Triticum aestivum L.) tohumlarına ön uygulama olarak jasmonik asit (2 mM JA) uygulaması yapılmış, 3 gün sonrada tuz (150 $\mathrm{mM} \mathrm{NaCl}$ ) uygulaması yapılmıştır. Araştırma sonucunda JA'in antioksidant enzimlerin aktivitesini ve antioksidatif bileşiklerin konsantrasyonunu artırarak buğday fidelerini tuz zararından etkili bir şekilde koruduğu belirlenmiştir (Qiu ve ark., 2013). $\mathrm{Bu}$ çalışma, farklı tuz ve jasmonik asit uygulamalarının yem bezelyesinin gelişimine etkisini belirlemek amacıyla yürütülmüştür.

\section{Materyal ve Yöntem}

Araştırma ortalama sıcaklığın $19.2^{\circ} \mathrm{C}$, ortalama nisbi nemin ise \% 55 olduğu laboratuvar şartlarında, saksı denemesi olarak 2016 yılında yürütülmüştür. Çalışmada yem bezelyesinin Gölyazı çeşidi kullanılmıştır. Çeşidin tuz stresine tepkisi Önal Aşcı ve Üney, (2017) tarafından yapılan çalışmada belirlenmiștir. Deneme Bölünmüș Parseller Deneme Desenine göre 5 tekrarlamalı kurulmuştur. Bitkilere 4 farklı tuz konsantrasyonu $(0,25,50,75 \mathrm{mM} \mathrm{NaCl})$ ve 3 farklı jasmonik asit (JA) konsantrasyonu $(0,50$, $100 \mu \mathrm{M}$ JA) uygulanmıştır. Elenmiş toprak (2 kg) doldurulan her saksiya 8 adet tohum ekilmiş, çimlenme gerçekleştikten sonra, her saksıda 4 bitki bırakılmıştır. Ekimle beraber her saksıya 50 ppm azot, 100 ppm fosfor ve 125 ppm potasyum (Korkmaz, 2015) verilmiştir. Fidelerde 4. gerçek yapraklar çıktığında JA yapraktan uygulanmıştır. JA uygulamasından 3 gün sonra saksılara tuz ilavesi yapılmıştır. Bitkilerde solma belirtileri gözlendiğinde ölçümler gerçekleştirilmiştir (Bitkiler yaklaşık 30 günlüktür). Araştırmada bitki boyu $(\mathrm{cm})$, kök uzunluğu $(\mathrm{cm})$, yaprakçık sayısı (adet/bitki), toprak üstü yaş ve kuru ağırlık (mg), kök yaş ve kuru ağırlık (mg), toplam klorofil miktarı (SPAD) ölçülmüştür. Bunların dışında yaprağın oransal su içeriği (Kuşvuran, 2010), prolin miktarı (Bates ve ark., 1973), membran zararlanması (Valentovic ve ark., 2006) belirlenmiştir. Verilerin normal dağılım kontrolü Kolmogorov-Smirnov testi, alt grupların varyanslarının homojenlik kontrolü Levene testi ile yapılmıştır. Elde edilen veriler, Bölünmüş Parseller Deneme Desenine göre 5 tekrarlamalı olarak analiz edilmiştir. Ana parselde tuz, alt parselde ise JA uygulaması yer almıştır. Farklı ortalamaların belirlenmesinde Tukey çoklu karşılaştırma testi kullanılmıştır. Hesaplamalarda ve yorumlamalarda \%5 önem düzeyi kullanılmıștır. Tüm hesaplamalar Minitab 17 istatistik paket programı ile yapılmıștır.

\section{Bulgular ve Tartışma}

Yapılan varyans analizi sonucunda; bitki boyuna sadece tuz dozlarının etkisi istatistiki olarak önemli bulunmuştur $(p<0,01)$. Çizelge 1 incelendiğinde görüleceği üzere, tuz uygulaması bitki boyunda azalmaya neden olmuş, tuz dozu arttıkça bitki boyu azalmış, kontrolle karşılaştırıldığında ilk önemli azalış $75 \mathrm{mM}$ dozunda gerçekleşmiştir. Toprakta fazla bulunan $\mathrm{NaCl}$ bitkilerde, fizyolojik kuraklık, toksik etki, besin elementi eksikliği, besin elementi dengesizliğine neden olarak bitki gelişimini olumsuz etkilemektedir (Çulha ve Çakırlar, 2011). Bilgili ve ark. (2011), yem bezelyesinde ekimle birlikte uygulanan $50 \mathrm{mM}$ NaCl'ün bitki boyunu kontrole (tuzsuz) göre önemli derecede azalttığını belirlemişlerdir. Aynı çeşidin kullanıldığı bir çalışmada ise bitki boyunda ilk önemli azalış 100 mm NaCl uygulamasında belirlenmiştir (Önal Aşcı ve Üney, 2017). Her ne kadar JA'in etkisi istatistiki olarak önemli bulunmasa da aynı çeşit kullanılarak yürütülen 2 çalışmada farklı sonucun elde edilmesi muhtemelen JA'in etkisiyle gerçekleşmiştir. JA'in bitkinin stres şartlarında oluşturduğu cevapları tetikleyici etki yaptığı bildirilmiştir (Günalp, 2011). Toprak üstü yaş ağırlık bakımından uygulanan tuz dozları arasında istatistiki olarak önemli farklılık $(p<0,01)$ bulunmuştur. Araştırmada bitkilere uygulanan $25 \mathrm{mM}$ tuz dozu toprak üstü yaş ağırlığı artırırken, diğer tuz dozlarında azalmıştır. Düşük tuz (25 mM) dozları bitkiler için besin etkisi yapmaktadır (Kacar ve ark., 2009). Bezelye ile yapılan başka bir çalışmada da $25 \mathrm{mM} \mathrm{NaCl}$ uygulaması bitkilerde yaş ağırlığı artırmıştır (Önal Aşcl ve Üney, 2017). Yüksek tuz dozları ise bitkinin topraktan su alımını azalttığından ve toksik etki 
yaptı̆̆ından (Çulha ve Çakırlar, 2011), tuz dozları toprak üstü yaş ağırlığı azaltmıştır. Farklı bitkilerle yapılmış çalışmalar sonucunda tuz uygulamasının toprak üstü yaș ağırlı̆̆ı azalttığı belirlenmiştir (Bora, 2015; Uyar, 2016; Önal Așcl ve Üney, 2017; Özkorkmaz ve Yılmaz, 2017; Önal Așcı ve Altun, 2018; Şimşek Soysal ve ark., 2018).

Çizelge 1. Farklı tuz dozlarında bezelyede belirlenen ortalama bitki boyu ve toprak üstü yaş ağırlık (TÜYA) değerleri.

\begin{tabular}{ccc}
\hline Tuz $(\mathrm{NaCl})$ dozu $(\mathrm{mM})$ & Bitki boyu $(\mathrm{cm})$ & TÜYA $(\mathrm{mg})$ \\
\hline 0 & $42.67 \mathrm{a}$ & $961.21 \mathrm{a}$ \\
25 & $40.54 \mathrm{ab}$ & $1000.70 \mathrm{a}$ \\
50 & $39.95 \mathrm{ab}$ & $908.66 \mathrm{a}$ \\
75 & $37.52 \mathrm{~b}$ & $554.61 \mathrm{~b}$ \\
\hline
\end{tabular}

Ortak harfi olmayan tuz dozları arasındaki fark istatistiksel olarak önemlidir $(\mathrm{p}<0.05)$

Yapılan varyans analizi sonucunda yaprakçık sayısı bakımından tuz x JA interaksiyonu istatistiki olarak önemli $(p<0,05)$ bulunmuştur. Hem tuz uygulaması hem de JA uygulaması bitkide yaprakçık sayısını azaltmıştır. Bu nedenle en fazla yaprakçık sayısı tuz ve JA uygulamasının yapılmadığı bitkilerde belirlenmiştir. Ancak iki faktör (JA ve $\mathrm{NaCl}$ ) birlikte uygulandığında bitkinin tuza toleransının bir miktar arttığı söylenebilir. Nitekim hem 50 hem de $100 \mu \mathrm{M}$ JA uygulamalarında, 25, 50 ve $75 \mathrm{mM}$ tuz uygulanan bitkilerin yaprakçık sayıları istatistiki olarak farksız bulunmuştur (Çizelge 2). Tuz stresi bitkilerde hücre bölünmesi ve uzamasını etkilemektedir. Bunun sonucu olarak da yaprak sayısında azalma meydana gelmektedir (Çulha ve Çakırlar, 2011). JA'in bitkinin stres şartlarında oluşturduğu cevapları tetikleyici etki yaptığı bildirilmiştir (Günalp, 2011). Nitekim, mısırda yapılan bir çalışmada tuz uygulaması, kontrol bitkilere göre yaprak büyümesini azaltmasına rağmen, tuz ve JA birlikte uygulanan bitkilerde yaprak uzaması, yalın tuz uygulamasından daha fazla gerçeklemiştir (Mir ve ark., 2018).

Yapılan varyans analizi sonucunda; kök yaş ve kuru ağırlığı bakımından tuz x JA interaksiyonu istatistiki olarak önemli $(p<0,05)$ bulunmuştur. Araştırmada hem tuz hem de JA uygulamasının doza bağlı olarak kök yaş ve kuru ağırlığında artış ve azalışlar meydana getirdiği görülmektedir. Araştırmamızda en yüksek kök yaş ve kuru ağırlı̆̆ $50 \mu \mathrm{M}$ JA ve 25 mM NaCl'ün birlikte uygulandığı bitkilerde belirlenmiştir (Tablo 2). Yapılan bir çalışmada metil jasmonat uygulanan ve tuz stresine maruz birakılan soya bitkilerinde, sadece tuz stresine maruz kalanlara göre içsel GA ve ABA hormon miktarları, kök yaş ve kuru ağırlığı artış göstermiştir (Yoon ve ark., 2009).

Çizelge 2. Farklı Tuz ve JA dozlarında bezelyede belirlenen ortalama yaprakçık sayısı, kök yaş ve kuru ağırlık değerleri

\begin{tabular}{ccccc}
\hline $\begin{array}{c}\text { Tuz }(\mathrm{NaCl}) \\
\text { dozu }(\mathrm{mM})\end{array}$ & $\begin{array}{c}\text { JA dozu } \\
(\mu \mathrm{M})\end{array}$ & $\begin{array}{c}\text { Yaprakçık } \\
\text { sayısı (adet) }\end{array}$ & $\begin{array}{c}\text { Kök yaş } \\
\text { ağırlı }(\mathrm{mg})\end{array}$ & $\begin{array}{c}\text { Kök kuru } \\
\text { ağırlı }(\mathrm{mg})\end{array}$ \\
\hline \multirow{2}{*}{0} & 0 & $11.78 \mathrm{Aa}$ & $637.50 \mathrm{Aa}$ & $41.67 \mathrm{Aa}$ \\
& 50 & $9.47 \mathrm{Ba}$ & $547.50 \mathrm{Ab}$ & $33.33 \mathrm{Ab}$ \\
& 100 & $9.30 \mathrm{Ba}$ & $728.33 \mathrm{Aa}$ & $51.67 \mathrm{Aa}$ \\
\hline \multirow{2}{*}{25} & 0 & $10.25 \mathrm{Ab}$ & $620.00 \mathrm{Aa}$ & $46.67 \mathrm{Ba}$ \\
& 50 & $10.20 \mathrm{Aa}$ & $887.50 \mathrm{Aa}$ & $72.50 \mathrm{Aa}$ \\
& 100 & $10.10 \mathrm{Aa}$ & $573.50 \mathrm{Aab}$ & $45.00 \mathrm{Ba}$ \\
\hline \multirow{2}{*}{50} & 0 & $10.48 \mathrm{Aab}$ & $710.83 \mathrm{Aa}$ & $59.17 \mathrm{Aa}$ \\
& 50 & $9.50 \mathrm{Aa}$ & $477.50 \mathrm{Ab}$ & $35.83 \mathrm{Bb}$ \\
& 100 & $10.13 \mathrm{Aa}$ & $414.17 \mathrm{Aab}$ & $40.83 \mathrm{ABa}$ \\
\hline \multirow{2}{*}{75} & 0 & $9.60 \mathrm{Ab}$ & $412.50 \mathrm{Aa}$ & $42.50 \mathrm{Aa}$ \\
& 50 & $9.33 \mathrm{Aa}$ & $265.83 \mathrm{Ab}$ & $38.33 \mathrm{Ab}$ \\
& 100 & $9.30 \mathrm{Aa}$ & $246.67 \mathrm{Ab}$ & $28.33 \mathrm{Aa}$ \\
\hline
\end{tabular}

Aynı tuz dozunda ortak büyük harfi olmayan JA dozları arasındaki fark istatistiksel olarak önemlidir $(\mathrm{p}<0,05)$

Aynı JA dozunda ortak küçük harfi olmayan tuz dozları arasındaki fark istatistiksel olarak önemlidir $(\mathrm{p}<0,05)$

Yapılan varyans analizi sonucunda, tuz ve JA uygulamalarının toprak üstü kuru ağırlığa, kök uzunluğuna, toplam klorofil miktarına, toprak üstü aksamda Na oranına, yaprağın oransal su içeriğine, yaprağın prolin içeriğine, yaprak hücrelerinde hücre membran zararlanma oranına istatistiki olarak etkisi ( $p>0,05)$ bulunmamıştır. Tuz stresi yaşayan bitkilerde, maruz kaldıkları tuz dozuna bağlı olarak, yukarıda bahsedilen parametreler genellikle önemli düzeyde etkilenmektedir. Yapılan çalışmalarda tuz stresinin bitkilerde toprak üstü kuru ağırlı ve kök uzunluğunu azalttığı, $\mathrm{Na}$ ve prolin birikimini artırdığı, yaprağın oransal su içeriğini azalttığı, hücre membranlarında ise zararlanmalar meydana getirdiği bildirilmektedir. Araştırmamızda söz konusu özelliklere tuz dozunun etkisinin önemsiz bulunması muhtemelen JA'in tuzun olumsuz etkilerini azaltıcı rolü ile ortaya çıkmıştır.

\section{Sonuç}

$\mathrm{Bu}$ çalışma sonucunda JA ve tuz uygulamasının yem bezelyesinin Gölyazı çeşidinde bitki gelişimine olan etkileri incelenmiştir. Tuz dozunun artması bitkide gelişimi genellikle olumsuz etkilemiş, JA'in ise uygulama dozuna bağlı olarak tuzun olumsuz etkisini bir miktar dengeleyebildiği düşünülmektedir. Ancak, tuzluluk ve JA'in bitki üzerindeki etkisini daha net ortaya koyabilmek için yeni araştırmalara ihtiyaç olduğu düşünülmektedir. 


\section{Kaynaklar}

Bates, L.S., Waldren, R.P., Teare, I.D., 1973. Rapid determination of free proline for water-stress studies. Plant and Soil, 39 (1): 205-207.

Bilgili, U., Budaklı Çarpıcı, E., Așık, B.B., Çelik, N., 2011. Root and shoot response of common vetch (Vicia sativa L.), forage pea (Pisum sativum L.) and canola (Brassica napus L.) to salt stress during early seedling growth stages. Turkish Journal of Field Crops, 16 (1): 33-38.

Bora, M., 2015. Değişik Vejetasyon Dönemlerine Kadar Uygulanan Farklı tuz konsantrasyonlarının biberde meydana getirdiği fizyolojik, morfolojik ve kimyasal değişikliklerin belirlenmesi. Namık Kemal Üniversitesi Fen Bilimleri Enstitüsü (Basılmamış), Yüksek Lisans Tezi. Tekirdağ, $92 \mathrm{~s}$.

Çulha, Ş., Çakırlar, H., 2011. Tuzluluğun bitkiler üzerine etkileri ve tuz tolerans mekanizmaları. Afyon Kocatepe Üniv. Fen Bilimleri Derg, 11: 11-34.

Demirkol, G., Yılmaz, N., Önal Așcl, Ö., 2019. Tuz stresinin yem bezelyesi (Pisum sativum ssp. arvense L.) seçilmiş genotipinde çimlenme ve fide gelişimi üzerine etkileri. Kahramanmaraş Sütçü İmam Üniversitesi Tarım ve Doğa Dergisi, 22(3): 354-359.

Dölarslan, M., Gül, E., 2012. Toprak bitki ilişkileri açısından tuzluluk. Türk Bilimsel Derlemeler D, 5(2): 56-59.

Ekmekçi, E., Apan, M., Kara, T., 2005. Tuzluluğun bitki gelişimine etkisi. Ondokuz Mayıs Üniversitesi Ziraat Fakültesi Dergisi, 20 (3):118-125.

Fedina, I.S., Tsonev, T.D., 1997. Effect of pretreatment with methyl jasmonate on the response of Pisum sativum to salt stress. Journal of Plant Physiology, 151 (6): 735-740.

Günalp, B., 2011. Patlıcan (Solanum melongena L.) Embriyo Kültüründe, Jasmonik Asit ve Tuz Stresi Etkileşiminin İncelenmesi. Ankara Üniversitesi Fen Bilimleri Enstitüsü (Basılmamış), Yüksek Lisans Tezi. Ankara, 77s.

Kacar, B., Katkat, V., Öztürk, Ş., 2009. Bitki Fizyolojisi (3. Baskı). Nobel Yayınları No: 848. Ankara, 556 s.

Korkmaz, K., 2015. Sözlü görüşme.

Kuşvuran, Ş., 2010 Kavunlarda kurakllık ve tuzluluğa toleransın fizyolojik mekanizmaları arasındaki bağlantılar. Çukurova Üniversitesi Fen Bilimleri Enstitüsü (Basılmamıș), Doktora Tezi. Adana, 356 s.
Mir, M.A., John, R., Alyemeni, M.N., Alam., P., Ahmad, P., 2018. Jasmonic acid ameliorates alkaline stress by improving growth performance, ascorbate glutathione cycle and glyoxylase system in maize seedlings. Sci Rep., doi: 10.1038/s41598-01821097-3.

Önal Așcl, Ö., Üney, H., 2017. Farklı NaCl konsantrasyonlarının bazı yem bezelyesi (Pisum arvense L.) çeșit ve genotiplerinde bitki gelişimine etkisi. ODU BAP, TF-1462 nolu proje kesin sonuç raporu.

Önal Așcl, Ö., Altun, M., 2018. Farklı NaCl Konsantrasyonlarının Bazı börülce (Vigna unguiculata L.) çeşitlerinde bitki gelişimine etkisi. ODU BAP, TF 1531 nolu proje kesin sonuç raporu.

Özkorkmaz, F., Yılmaz, N., 2017. Farklı tuz konsantrasyonlarının fasulye (Phaseolus vulgaris L.) ve börülcede (Vigna unguiculata L.) çimlenme üzerine etkilerinin belirlenmesi. Ordu Üniversitesi Bilim ve Teknoloji Dergisi, 7(2): 196-200.

Öztürk A., 2004 Tuzluluk ve sodyumluluğun oluşumu, bitki ve toprağa etkileri. Sulanan Alanlarda Tuzluluk Yönetimi Sempozyumu (20-21 Mayıs, 2004) Bildiri Kitabı, 1-16.

Qiu, Z., Guo, J., Zhu, A., Zhang, L., Zhang, M., 2014. Exogenous jasmonic acid can enhance tolerance of wheat seedlings to salt stress. Ecotoxicology and Environmental Safety, 104: 202-208.

Şimşek Soysal, A.Ö., Demirkol, G., Önal Aşcı, Ö., Kaşko Arıcı, Y. Acar, Z., Yılmaz, N., 2018. Tuz stresinin Sorgum $\times$ Sudanotu melezinde çimlenme ve fide gelişim özelliklerine etkisi. Uluslararası Tarım ve Yaban Hayatı Bilimleri Dergisi, 4(2): 247- 252.

TÜIKK, 2018.Bitkisel Üretim İstatistikleri. (Web page: http://www.tuik.gov.tr (Erişim tarihi: 03.12.2018).

Uyar, H., 2016. Hamburg Misketi (V. vinifera L.) ve isabella (V. labrusca) Üzüm Çeşitlerinin Tuz Stresine Toleranslarının Belirlenmesi. Ordu Üniversitesi Fen Bilimleri Enstitüsü (Basılmamış), Yüksek Lisans Tezi. Ordu, $62 \mathrm{~s}$.

Valentovic, P., Luxova, M., Kolarovic, L., Gasparikova, O., 2006. Effect of osmotic stress on compatible solutes content, membrane stability and water relations in two maize cultivars. Plant Soil Environment, 52 (4): 186-191.

Yoon, J.Y., Hamayun, M., Lee S-K., Lee, I-J., 2009. Methyl jasmonate alleviated salinity stress in soybean. J. Crop Sci. Biotech., 12 (2): 63-68. 